\title{
Successfully opening an in-stent chronic total occlusion lesion of the right coronary artery in a patient with peripheral artery disease
}

\author{
(D)Marijana Knežević \\ Praveček ${ }^{1 *}$, \\ (iD Krešimir Gabaldo', \\ DeKatica Cvitkušić \\ Lukenda', \\ (D)Božo Vujeva', \\ DIvica Dunđer', \\ (D)Antonija Raguž'1, \\ (iDTomislav Krčmar ${ }^{2,3}$, \\ (1DBoris Starčevićc
}

${ }^{\top}$ General Hospital „Dr. Josip Benčević“ Slavonski Brod Slavonski Brod, Croatia

2University Hospital Centre Rijeka, Rijeka, Croatia

${ }^{3}$ University Hospital Centre Zagreb, Zagreb, Croatia

${ }^{4}$ University Hospital Dubrava,

Zagreb, Croatia

\section{RECEIVED:}

February 18, 2020

ACCEPTED:

February 22, 2020

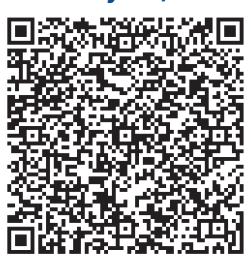

$\square$ Cardiologia Croatica 2020;15(3-4):48
KEYWORDS: chronic total occlusion, in-stent restenosis, percutaneous coronary intervention, peripheral artery disease.

CITATION: Cardiol Croat. 2020;15(3-4):48. | https://doi.org/10.15836/ccar2020.48

*ADDRESS FOR CORRESPONDENCE: Marijana Knežević Praveček, Odjel Kardiologije, OB J. Benčević, A. Štampara 42, HR-35000 Slavonski Brod, Croatia. / Phone: +385-98-550-328 / E-mail: marijana@aip.hr

ORCID: Marijana Knežević Praveček, https://orcid.org/0000-0002-8727-7357

Krešimir Gabaldo, https://orcid.org/0000-0002-0116-5929 • Katica Cvitkušić Lukenda, https://orcid.org/0000-0001-6188-0708 Božo Vujeva, https://orcid.org/0000-0003-0490-3832 • Ivica Dunđer, https://orcid.org/0000-0002-3340-7590 Antonija Raguž, https://orcid.org/0000-0002-7032-2852 • Tomislav Krčmar, https://orcid.org/0000-0003-4689-1673 Boris Starčević, https://orcid.org/0000-0002-3090-2772

|IIIIIIIIIIIIIIIIIIIIIIIIIIIIIIIIIIIIIIIIIIIIIIIIIIIIIIIIIIIIIIIIIIIIIIIIIIIIIIIIIIIIIIIIIIIIIIIIIIIIIIIIIIIIIIIIIIII

Introduction: There are limited study data available of the effects of peripheral artery disease (PAD) on patients undergoing chronic total occlusion (CTO) percutaneous coronary intervention (PCI). According to the PROGRESS-CTO Registry results patients with PAD undergoing CTO PCI have more comorbidities, more complex lesions and lower procedural success. ${ }^{1-3}$ We present the case of successful opening in-stent CTO lesion of right coronary artery (RCA) in patient with PAD.

Case report: 59-year-old man with a known history of a coronary vessel disease and PAD presented to our department due to frequent episodes of chest pain under minimal exercise and claudication and pain in the buttocks. The coronary angiography showed unchanged exam in left coronary basin. The RCA was completely occluded in segment two right in the area of the stent that was implanted eight years before. We found collaterals from the left coronary artery system and signs of calcification and autocollaterals for the distal segment of RCA, so the diagnostically criteria of a CTO were fulfilled. Because of the present symptoms of the patient and evidence for vital myocardium by echocardiography and myocardial scintigraphy revascularization of the CTO was performed. An AL $0.756 \mathrm{~F}$ guidance catheter was used and the standard antegrade wire escalation technique attempted. A Turnpike Spiral catheter was inserted with the help of a ASAHI Fielder XT-A wire which was exchanged to an ASAHI Gaia Second which allowed the successful recanalization. Balloon angioplasty was performed with Abbot Traveler 1.5/15mm, Medtronic Euphora 2.57/15mm. Two sirolimus eluting stents (Terumo Ultimaster $3.0 / 38 \mathrm{~mm}$ and Ultimaster $3.0 / 30 \mathrm{~mm}$ ) were successfully implanted with very good angiographic result. Three months later, chronic total occlusion of the left external iliac artery was treated successfully by percutaneous intervention and control coronary angiography showed unchanged exam in RCA.

Conclusion: Our experience in this case demonstrates the feasibility of recanalization of an in-stent CTO in the patient with PAD and three months follow up showed improved of angina and quality of life. There is a definite and strong correlation between PAD and CAD. A concurrent PAD diagnosis is associated with higher rates of adverse outcomes following CTO PCI which requires additional monitoring.

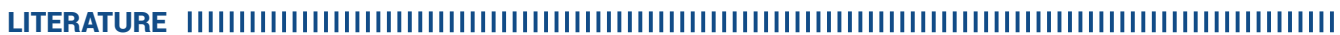

1. Xenogiannis I, Gkargkoulas F, Karmpaliotis D. Alaswad K, Krestyaninov 0, Khelimskii D, et al. The Impact of Peripheral Artery Disease in Chronic Total Occlusion Percutaneous Coronary Intervention (Insights From PROGRESS-CTO Registry). Angiology. 2020 Mar;71(3):274-280. https://doi.org/10.1177/0003319719895178

2. Ybarra LF, Cantarelli MJC, Lemke VMG, Quadros AS. Percutaneous Coronary Intervention in Chronic Total Occlusion. Arq Bras Cardiol. 2018 May:110(5):476-483. https://doi.org/10.5935/abc.20180077

3. Karmpaliotis D, Hatem R. In-Stent CTO, Not as Easy as it Looks. JACC Cardiovasc Interv. 2017 May 8;10(9):903-905. https://doi.org/10.1016/j.jcin.2017.02.038 